\title{
Implications of Inadequate Water and Sanitation Infrastructure for Community Spread of COVID-19 in Remote Alaskan Communities
}

\author{
Laura Eichelberger ${ }^{\mathrm{a}}$, Subhabrata Dev ${ }^{\mathrm{b}}$, Tricia Howe ${ }^{\mathrm{a}, \mathrm{c}}$, David L. Barnes ${ }^{\mathrm{b}, \mathrm{d}}$, Eric Bortz ${ }^{\mathrm{e}}$, Brandon
} R. Briggs ${ }^{\mathrm{e}}$, Patricia Cochran ${ }^{\mathrm{f}}$, Aaron D. Dotson ${ }^{\mathrm{g}}$, Devin M. Drown ${ }^{\mathrm{h}, \mathrm{i}}$, Micah B. Hahn', Kaitlin Mattos ${ }^{k, 1}$, Srijan Aggarwal ${ }^{\text {b,d* }}$

aNational Tribal Water Center, Alaska Native Tribal Health Consortium, Anchorage, AK 99508, United States

binstitute of Northern Engineering, University of Alaska Fairbanks, Fairbanks, AK 99775, United States

cAlaska Pacific University, Anchorage, AK 99508, United States

${ }^{\mathrm{d} D e p a r t m e n t}$ of Civil, Geological, and Environmental Engineering, University of Alaska Fairbanks, Fairbanks, AK 99775, United States

eDepartment of Biological Sciences, University of Alaska Anchorage, Anchorage, AK 99508, United States

${ }_{\mathrm{f}}$ Alaska Native Science Commission, P.O. Box 244305, Anchorage, AK 99524, United States

'Department of Civil Engineering, University of Alaska Anchorage, Anchorage, AK 99508, United States

hDepartment of Biology and Wildlife, University of Alaska Fairbanks, Fairbanks, AK 99775, United States

institute of Arctic Biology, University of Alaska Fairbanks, Fairbanks, AK 99775, United States

IInstitute for Circumpolar Health Studies, University of Alaska Anchorage, Anchorage, AK 99508, United States

${ }^{\mathrm{k} C i v i l, ~ E n v i r o n m e n t a l}$ and Architectural Engineering, University of Colorado Boulder, Boulder, CO, 80309, United States

'Division of Environmental Health and Engineering, Alaska Native Tribal Health Consortium, Anchorage, AK 99508, United States

Manuscript Preprint

\section{*Corresponding author}

Srijan Aggarwal, 1764 Tanana Loop, Civil Geological and Environmental Engineering Department, College of Engineering and Mines, University of Alaska Fairbanks, Fairbanks, AK 99779, United States. Email: saggarwal@alaska.edu 


\section{Abstract}

The novel coronavirus SARS-CoV-2, the causative agent of COVID-19, emerged in the human population in December 2019 and spread worldwide within a few short months. Much of the public health focus for preventing and mitigating the spread of COVID-19 has been on individual and collective behaviors, such as social distancing, mask-wearing, and hygiene. Yet it is equally important to recognize that these behaviors and health outcomes occur within broader social and environmental contexts. Factors within local communities, regional policy, race, history, personal beliefs, and natural- and built environmental characteristics affect underlying population health and the spread of disease. For example, COVID-19 has renewed attention to secure water and sanitation services and their importance in protecting human health. Many remote Alaskan communities are particularly vulnerable because of inadequate water and sanitation systems. In this paper, we describe how inadequate water and sewer services may place the inhabitants of remote Alaskan communities at higher risk of COVID spread. We argue that insufficient water security and inadequate sewer systems, along with household overcrowding, multigenerational residences, limited transportation options, limited medical facilities, and higher prevalence of chronic diseases could lead to a greater potential of COVID-19 transmission and to more severe disease outcomes in these communities.

Keywords: COVID-19, Alaska Native, water security, sanitation.

\section{Introduction}

Coronavirus disease 2019 (COVID-19) is caused by a novel pathogen (SARS-CoV-2) that emerged from a zoonotic reservoir to infect humans in late 2019 in Wuhan, China, spreading across the globe by mid-summer 2020 through efficient human-to-human transmission (R. Lu et al., 2020; Zhu et al., 2020). COVID-19 has brought renewed attention to the importance of water and sanitation infrastructure to protect human health, and the global inequities that exist in household water security (e.g. Staddon et al., 2020). Access to piped water and sanitation infrastructure primarily reduces the transmission of SARS-CoV-2 by allowing for frequent handwashing and by reducing the contact that individuals have with wastewater. However, according to United Nations estimates, $75 \%$ of households in low-and middle-income countries lack the ability to hand wash with water and soap, and more than $50 \%$ of the world population does not have sufficient sanitation (UNICEF, 2019). Many scholars have recently connected the risk of SARS-CoV-2 infection with these dismal statistics on household water insecurity in low- and middle-income countries, particularly in crowded urban slums (Rafa et al., 2020; Roy et al., 2020; Smiley et al., 2020; Stoler et al., 2020; Zar et al., 2020).

The true burden of household water insecurity, however, extends beyond low-income countries. Household water insecurity also impacts hundreds of thousands of people in higher income countries of the Global North, including the United States (e.g., Deitz and Meehan, 2019; Riggs et al., 2017). A recent analysis of COVID-19 cases on American Indian Reservations and Tribal homelands in the contiguous United States found that the primary risk factor behind the incidence of COVID-19 in these populations is a lack of indoor plumbing (Rodriguez-Lonebear et al., 2020). This problem is acute in Alaska, where about $22 \%$ of homes in remote Alaskan communities (that lie off the state's limited road system) lack in-home plumbing (DHSS, 2020a), compared to less than $1 \%$ nationally (Meehan et al., 2020).

Much of the current focus for preventing and mitigating the spread of SARS-CoV-2 has been on individual and collective behaviors, such as social distancing, mask-wearing, and hygiene. Yet it 
is equally important to recognize that these behaviors and health outcomes are nested within a broader eco-social context that includes factors at the local, regional, and national levels, such as policy, history, race, and natural and built environmental characteristics that affect the health of the underlying population and the spread of disease (Chen and Krieger, 2020; Gravlee, 2020; Joseph et al., 2020; Krieger, 2020).

In this paper, we describe how insecurities of water and sanitation at household- and community level contribute to an increased risk of SARS-CoV-2 transmission in remote Alaska Native communities. We argue that the lack of reliable and adequate access to water and sanitation infrastructure, coupled with overcrowding of homes, lack of transportation options (and associated expense) to the hub communities, limited medical facilities, and higher prevalence of chronic diseases, leads to a greater potential of SARS-CoV-2 transmission and to more severe COVID-19 disease outcomes if introduced into these communities. We conclude by describing how communities and Tribal Health Organizations are urgently seeking to address these insecurities of water and sanitation during the COVID-19 pandemic.

\section{SARS-COV-2 Infection and Transmission Routes}

SARS-CoV-2 infection. SARS-CoV-2 is a human betacoronavirus with a single-stranded RNA genome, and an enveloped spherical virion $(\sim 120 \mathrm{~nm})$ studded with a 9-12 $\mathrm{nm}$ long surface spike (S) glycoprotein (Bar-On et al., 2020; Bhowmick et al., 2020; R. Lu et al., 2020). SARS-CoV-2 S protein binds to angiotensin-converting enzyme 2 (ACE2) receptors on cells leading to infection of respiratory tissues, lungs, and occasionally other organs (Lan et al., 2020). SARS-CoV-2 typically causes a respiratory disease (COVID-19) with a wide spectrum of inflammatory and physiological manifestations (Shang et al., 2020; Zhu et al., 2020). Mild COVID-19 can be virtually asymptomatic, whereas moderate to severe COVID-19 is characterized by diffuse alveolar damage and bilateral pneumonia that can lead to acute respiratory distress and death (Richardson et al., 2020; Zhu et al., 2020). Underlying chronic co-morbidities, including hypertension, obesity, and diabetes, are found in a large fraction of hospitalized patients with COVID-19 (Richardson et al., 2020). Notably, driven by co-morbidities, the American Indian/Alaska Native (AIAN) population in Alaska has suffered a 5-fold higher rate of hospitalization from severe COVID-19 than the white population in Alaska (Frick and Watkins, 2020). While robust immune responses, including antibody and $T$ cell mediated memory responses, are generated even in mild infections, the duration and efficacy of immune responses upon secondary challenge are not known (Altmann and Boyton, 2020). At present, no approved vaccine is widely available against SARS-CoV-2, although several vaccine candidates have advanced to late-stage clinical trials (Krammer, 2020).

SARS-CoV-2 transmission. The transmission of SARS-CoV-2 is characterized by the basic reproduction number $\left(\mathrm{R}_{0}\right)$ of 1.40-6.49, which is comparatively higher than that of other severe beta-coronaviruses (SARS-CoV, MERS-CoV) and influenza viruses (Petersen et al., 2020; Rahman et al., 2020). While not completely understood, it is thought that the transmission of SARS-CoV-2 occurs through multiple mechanisms including cough/sneeze droplets from an infected person, contact with body parts or clothes of infected persons (Hijnen et al., 2020), contact with surfaces contaminated with SARS-CoV-2 due to settled droplets (Chia et al., 2020), and by micro-aerosols produced from respiratory droplets of infected persons due to sneezing, coughing, talking, or normal breathing. It is reported that these micro-aerosols can remain suspended in the 
134 air for 1-3 hours at room temperature $\left(21-23{ }^{\circ} \mathrm{C}\right)$ and relative humidity of $65 \%$, and is likely the dominant mode of SARS-CoV-2 transmission (Aboubakr et al., 2020).

136

137

138

139

140

141

142

143

144

145

146

147

148

149

150

151

152

153

154

155

156

157

158

159

160

161

162

163

164

165

166

167

168

169

170

171

172

173

174

175

176

\section{SARS-COV-2 in Wastewater}

SARS-CoV-2 and wastewater-based epidemiology. In some human cases, SARS-CoV-2 can infect the gastrointestinal (GI) tract and the live virus can be excreted into wastewater (raw sewage), although contribution of this mode of infection to human disease is unclear. SARS-CoV2 has been found to retain a degree of viability in fecal matter, and viral RNA has been detected in wastewater (Cheung et al., 2020; Medema et al., 2020). The role of contaminated wastewater in the risk and spread and persistence of COVID-19 in communities is poorly understood (Kitajima et al., 2020). Urban wastewater processing is thought to be generally refractory to survival of live SARS-CoV-2, although non-infectious remnants of viral RNA persist in wastewater (Kitajima et al., 2020; Medema et al., 2020). However, in rural Alaska, unprocessed waste disposal methods may increase the chances of live virus persistence and risk of human contact infection. The approach to understand the spread of a disease in a given community/watershed by testing for its signal in municipal wastewater is known as wastewater-based epidemiology (WBE). It has previously been employed to investigate the incidence of poliovirus (Lodder et al., 2012), norovirus (Kazama et al., 2016) and fingerprint of myriad other community- or watershed-level activities that are ultimately reflected in wastewater including use of pharmaceuticals and personal care products, consumption of doping substances, and exposure to pesticides (Choi et al., 2018; Lorenzo and Picó, 2019). Thus, raw or even processed wastewater is a potentially important environmental signal for COVID-19 infection in the humans in a community (Ahmed et al., 2020; D. Lu et al., 2020; Mao et al., 2020; Murakami et al., 2020). SARS-CoV-2 has also been reported in river water (Quito, Ecuador) that received untreated sewage (Guerrero-Latorre et al., 2020), indicating importance of water sanitization infrastructure in preventing the transmission of SARSCoV-2 via the sewer system.

Fecal-oral transmission of $\boldsymbol{S A R S - C o V - 2 . ~ S A R S - C o V - 2 ~ c a n ~ i n f e c t ~ t h e ~ g a s t r o i n t e s t i n a l ~ ( G I ) ~ t r a c t ~}$ and cause intense GI and hepatobiliary symptoms (D'Amico et al., 2020). Although the fecal-oral transmission of SARS-CoV-2 has not been reported to date, recent studies detected SARS-CoV-2 in the feces of an infected person (Kim et al., 2020; Xiao et al., 2020). The related SARS-CoV exhibited transmission by a fecal-oral route (Esper et al., 2010; Isakbaeva et al., 2004; Jevšnik et al., 2013). During the SARS outbreak in 2003, aerosolized SARS-CoV particles from floor drains spread into the bathroom of an adjacent apartment building (in multi-unit housing) (McKinney et al., 2006). Meanwhile, the presence of RNA fragments of SARS-CoV-2 in feces, anal swabs, and urine from infected persons has been reported in several studies (Chen et al., 2020; Kipkorir et al., 2020; Peng et al., 2020). While these studies indicate a serious concern about the capability of SARS-like coronaviruses to spread via wastewater and suggest the possibility of a fecal-oral route of transmission for SARS-CoV-2, as of the time of this writing, this mode of transmission has not been commonly detected in the spread of COVID-19 outside of hospital settings (D'Amico et al., 2020).

Recent evidence of SARS-CoV-2 in wastewater in Alaska. Capacity for wastewater sampling, laboratory processing, and validation of a COVID-19 PCR detection assay was developed at the University of Alaska. SARS-CoV-2 RNA was detected in a major community in interior Alaska in July 2020, corresponding to an increase in the epidemic curve in human COVID-19 cases. 
SARS-CoV-2 RNA was also detected in a smaller, isolated communities in Alaska with a low number of human cases (B. Briggs, pers. comm.; data not shown). These preliminary studies suggest the utility of this method as an environmental signal for SARS-CoV-2 prevalence to detect unrecognized COVID-19 cases in the community. Genomic tracking of SARS-CoV-2 in wastewater is also possible with application of advanced next-generation sequencing (short read NGS) technology, and has been found to mirror the human diversity of genome variants in the community (Crits-Christoph et al., 2020).

\section{The Eco-social Context of Remote Alaska}

Remote communities, poverty, and unemployment. Alaska is characterized by a widely dispersed population with more than 60,000 people living in remote communities of fewer than 1,000 residents that are located off the road system and are only accessible by plane or boat, including the Alaska Marine Highway System. The majority of these residents are Alaska Native. Census data indicates that poverty rates in American Indians and Alaska Natives (AIAN) communities can be almost double the U.S. average (Pindus et al., 2017), and the rates of unemployment are also significantly higher.

Overcrowding in rural Alaskan homes. It is sometimes said that there is little homelessness in remote Alaska because families move in together, creating multi-generational, multi-family households. In remote Alaska, $25-40 \%$ of households are overcrowded, compared to the national average of less than 5\% (Wiltse and Madden, 2018). According to the U.S. Department of Housing and Urban Development's (HUD), an "overcrowded" home is defined as having more than one person per room (Blake et al., 2007). Home overcrowding in rural Alaska presents challenges to limiting the spread of the virus once a family member becomes ill with COVID-19. The lack of space restricts the isolation of these family members exposing additional family members to the virus.

Implications of remoteness on COVID spread. Many residents in the rural communities are employed in seasonal or shift work that requires intrastate travel from their homes to fisheries, mines, oil fields, and other distant/remote workplaces. For example, more than $70 \%$ of workers in the North Slope Borough come from another borough or census area within Alaska (Krieger, 2019) as the well-paid jobs in the oil and gas industry on the Slope attract Alaskans from all over the state. Many of these workplaces employ labor from outside Alaska (about $20 \%$ of all workers in Alaska are nonresident; Krieger (2019)) presenting an additional exposure and transmission risk to rural Alaskans as village residents travel between work and home. Hunting, fishing, and gathering food and water, activities that depend on collective labor and inter-village travel, are essential for household food security, social connection, and cultural wellbeing. Residents make regular trips to larger communities to purchase food, fuel, and other household needs at lower prices.

Additionally, the hub-and-spoke Tribal healthcare system requires patients to travel regionally for medical care that is unavailable at local clinics. Regional "hub" communities have larger populations (several thousand) compared to smaller surrounding villages and serve as the centers for primary health care and transportation services in their respective regions. Patients requiring more specialized medical care or hospitalization usually must travel on commercial airplanes to nearby cities (e.g., Anchorage, Fairbanks). COVID-19 outbreaks in remote Alaskan communities 
with inadequate medical facilities could present a dire situation that places a heavy burden on local commercial air carriers that may only land at some communities a few times per week. As an extreme example, transportation to and from the community of Little Diomede, Alaska is limited to a few months in the summer for small boats when the Bering Strait is free of sea ice, in the winter when planes can land on the sea ice, and the rest of the year by helicopter. Moreover, several air carriers that serve remote Alaska have taken a heavy financial blow due to COVID-19-related travel restrictions, further limiting transportation options to larger medical facilities.

Like many communities across the Arctic, the remoteness of communities provided some protection from transmission during the early stages of the pandemic, as city and Tribal governments were able to limit travel in and out of their communities (Bennett, 2020). As the pandemic progressed, and travel restrictions were eased, cases of COVID-19 began to rise in Alaska's remote regions. Although regional and community-led efforts to limit non-essential travel into and between remote villages have been in place, limitations in testing capabilities as well as legal limits on enforcement have impeded the ability of communities to avoid the introduction of SARS-CoV-2 into communities. For example, In late October 2020, the western Alaska village of Chevak (pop. $\sim 1,000$ residents) reported a sudden surge in cases with nearly $20 \%$ of population infected with SARS-CoV-2 virus (Kim, 2020). By late November 2020, all rural regions in Alaska were reporting "high" (>10 cases/100,000) 14-day averaged daily case rates with Yukon Kuskokwim-Delta region reporting a case rate around 150 per 100,000 (DHSS, 2020b).

\section{Household Insecurities of Water and Sanitation in Remote Alaskan Communities}

Over 3300 homes in more than 30 of the 190 remote Alaskan communities lack in-home piped water and sewer services, and another 16 are considered "underserved" with $20-50 \%$ of homes lacking connection to piped services (ADEC, 2013; DHSS, 2020a). Additionally, a report by Pettit (2014) points out that $18 \%$ of AIAN households in selected AIAN counties in Alaska had incomplete plumbing and 15\% lacked complete kitchen facilities. Residents of unplumbed homes either receive treated water through a closed truck haul service, or they self-haul water in limited amounts from a local watering point or washeteria (usually 5-30 gallons at a time) on foot using a wheelbarrow or sled or by snow machine or four-wheeler (Fig. 1A). In self-haul households, household water quantity used is typically less than 5 gallons per person per day (gpcd) (Eichelberger, 2018; Mattos et al., 2020; Thomas et al., 2016), far less than the WHO recommendation of 13.2 gpcd for intermediate water access (Howard and Bartram, 2003). A recent study found that $80 \%$ of participating households reported reusing washbasin water an average of 3 times before changing the water (Mattos et al., 2020), which may increase pathogen exposure (CDC, 2020). Limited access to water in remote Alaskan communities contributes to a significantly higher risk of respiratory infections (Hennessy et al., 2008; Mosites et al., 2020). For example, compared to regions with greater coverage of in-home plumbing, hospitalization rates of children living in unplumbed communities is 3.4 times greater for respiratory syncytial virus (under the age of 5 years) and 30\% higher for pneumonia among infants (Hennessy et al., 2008).

Reliable access to clean water and sanitation services in both piped and unpiped communities is negatively affected by environmental factors, including extreme cold, permafrost, and increasingly - climate change (Brubaker et al., 2011; Eichelberger, 2019; Sohns et al., 2020). For example, utility systems in remote cold region communities face additional challenges because of continuous and discontinuous permafrost, a changing climate that leads to ground instability on 
263

264

265

266

the surface and subsurface, degradation of permafrost that leads to operation and maintenance issues, high costs of maintenance and risks for users (Smith, 1996). Climate change is contributing to problems such as poor water quality, high turbidity, loss of raw water sources, and damage to piped water and sewer infrastructure.
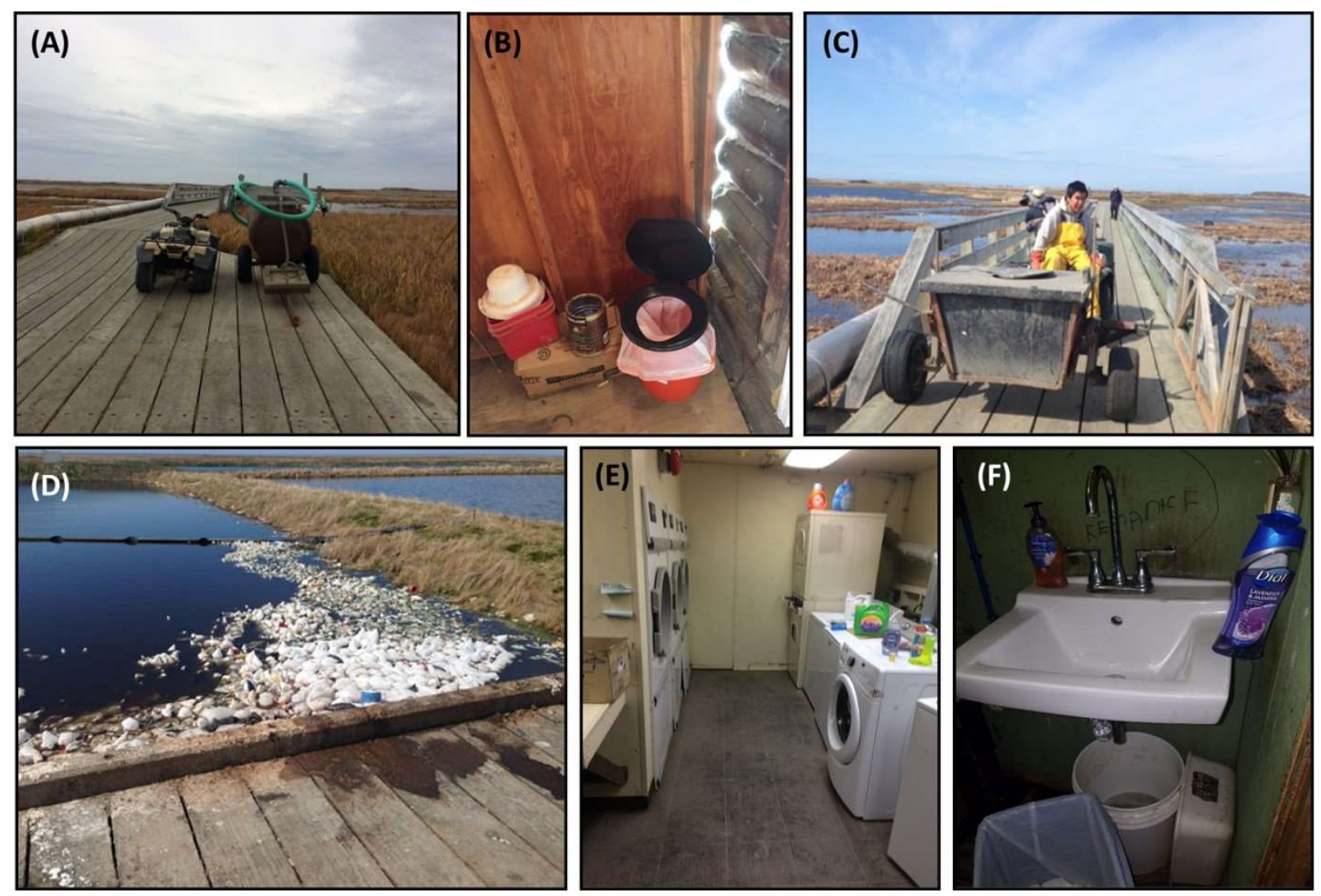

Figure 1. Water and sanitation infrastructure in rural Alaska. (A) hauling of water using a fourwheeler, (B) honey bucket, (C) hoppers, (D) sewage lagoons, (E) community washeteria, and (F) a slop bucket for sink drain collection. (picture credits: Aaron Dotson, Kaitlin Mattos)

Dilapidating washeterias and community contact locations. For many in unplumbed homes, central community facilities, or "washeterias" (Fig. 1E) provide a critical access point for access to treated water, showers, and laundry (often for a fee). These buildings are usually attached to or housed within the water treatment plant. Several washeterias in rural Alaska have outstanding repair needs but the state and federal support to address such needs has been shrinking over the years (e.g., ADEC, 2013). Many operate at a deficit because of operational costs involved. Others, such as the facility in Newtok, Alaska, are unable to provide service due to inadequate community energy infrastructure (Eichelberger, 2019). Since the start of the COVID-19 pandemic, those who manage washeterias have had to limit access to maintain social distancing. Under conditions of limited access for laundry, households share household washers and dryers thereby increasing their social contacts (Eichelberger, 2019, 2011, 2010; Jepson et al., 2017) - a practice that may increase the potential for exposure to SARS-CoV-2.

Disposal of 'honey buckets' and greywater. In unpiped communities where pit latrines ("outhouses") are not feasible (due to environmental factors such as high water tables and 
permafrost), residents use 5-gallon bucket latrines (known as "honey buckets") (Fig. 1B) and manually dispose of the collected human waste in centralized collection containers known as hoppers (Fig 1C) or directly in minimally controlled dumps or sewage lagoons (Fig. 1D). Many homes lack delineated bathrooms to defecate or practice personal hygiene privately. Honey buckets may sit in the entryway separated by a door to the outside and interior, or in the corner of a room separated by a sheet or curtain from the rest of the room. Particularly in communities without collection services, bags of human waste often accumulate outside of homes for days or weeks while they await transport to the dump or honey bucket lagoon.

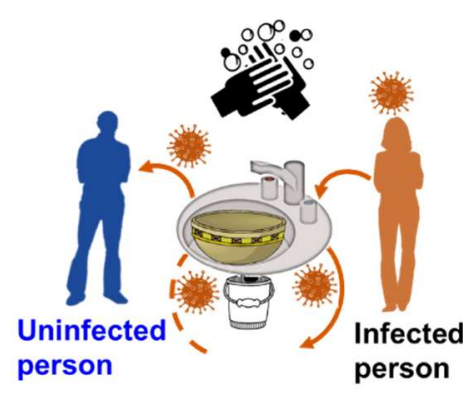

Reuse of sink wash water

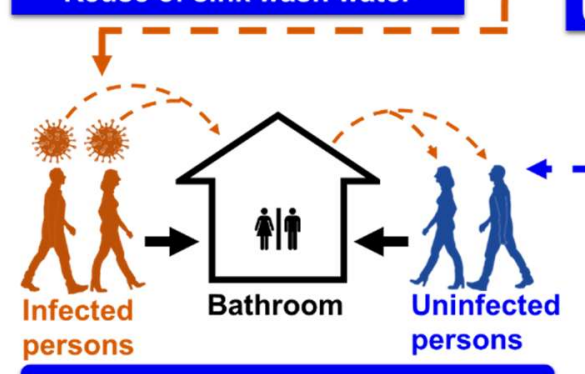

Common bathrooms

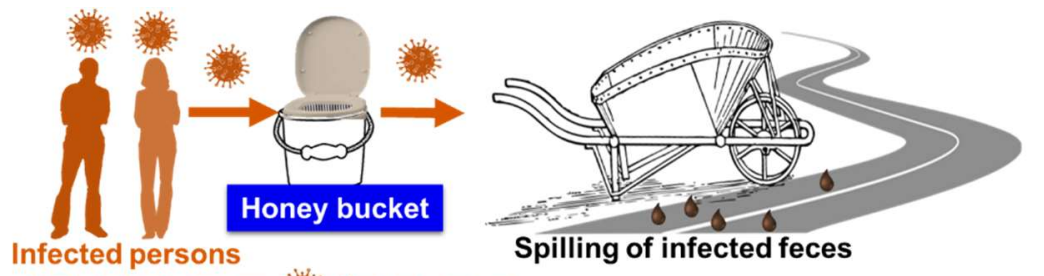

Hauling of wastes

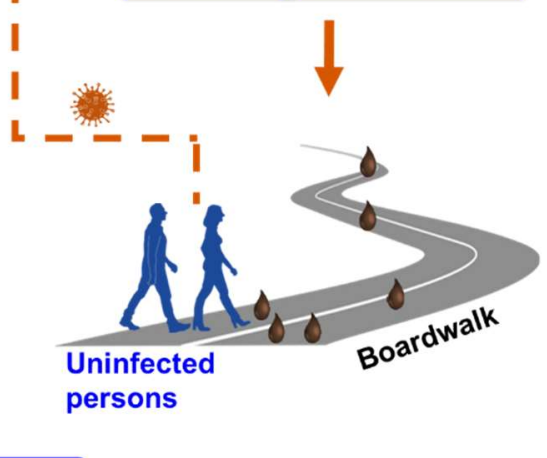

Community washeteria

A recent study of two unplumbed remote Alaskan communities found that bags of sewage sit outside of homes an average of 4-13 days, depending upon the season (Mattos et al., 2020). It is common for bags to break or get ripped open by animals, spilling their contents near homes. Collected waste can also be spilled during transport to hoppers or dumps, exposing the population to raw sewage from across the community (Chambers, 2008; Chambers et al, 2009). These hoppers also leak as they are often conveyed to the dump off the main pathways like board walks to avoid spilling to trafficked areas but resulting in spills adjunct to these areas. The lack of proper sanitation facilities and manual transport of human waste in rural Alaska could thus pose a potential infection risk via water or aerosol pathway (Bogler et al., 2020), though there is no evidence yet for fecal-oral transmission of SARS-CoV-2 (D'Amico et al., 2020).

Similarly, households that haul their water must also manually dispose of their greywater. Residents typically collect greywater in a basin or slop bucket (Fig. 1F) and dump it in a convenient place outside of the home, often on the ground not far from foot and vehicle pathways. Some households connect a floor pipe to their sinks and dispose of the water on the ground underneath their raised foundation. It is possible that pathogens in greywater can then be picked up by individuals who come into direct contact with the disposal areas (e.g., Chambers et al., 2009).A schematic showing potential transmission routes is presented in Fig 2. Additionally, the sanitation 
practices associated with sewage collection and disposal discussed here can lead to comorbidities or pre-existing conditions that can impact the severity of COVID-19.

\section{Preventing COVID-19 in a Water Insecure Context}

The COVID-19 pandemic has highlighted the long-standing inequities in Indigenous communities throughout the U.S (Hathaway, 2020; Kakol et al., 2020; van Dorn et al., 2020; Wilder, 2020), including in water and sanitation infrastructure. By July 2020, Tribal communities in the contiguous U.S. had over four times the incidence of COVID-19 cases compared to the rest of the U.S. with much of this discrepancy likely due to lack of indoor plumbing (Rodriguez-Lonebear et al., 2020). The Navajo Nation experienced a high death rate per capita early in the pandemic, exacerbated by the lack of safe water sources on the reservation (Abou-Sabe et al., 2020). Temporary hand washing stations, strict stay-at-home curfews, widespread mask usage, and substantial testing efforts have helped limit continued spread of the virus, but long lines at water filling stations and water rationing limit people's ability to take basic precautions against transmission of SARS-CoV-2 and other pathogens (Abou-Sabe et al., 2020; James, 2020).

In Alaska, community leaders recognized early the need to mitigate water insecurity to prevent the spread of SARS-CoV-2 in their communities. Regional entities and Tribal health organizations worked together to bulk order and distribute hand sanitizer, bleach, and other sanitary supplies to remote communities. In the Northwest Arctic Borough, special efforts were made to prioritize the distribution of hand sanitizer to homes without indoor plumbing. Tribal health organizations circulated instructions (e.g., YKHC, 2020) to water plant operators for how to make household bleach, which was distributed free of charge to community members.

Furthermore, the COVID-19 pandemic has brought attention to the human right to water and sanitation. Water and sewer utilities in Western Alaska have waived fees to encourage residents to use more water for hygiene and to facilitate sanitary disposal of waste (KYUK, 2020). In March 2020, the Alaska Rural Utility Collaborative began reconnecting homes that had been disconnected from running water services due to nonpayment. Others have used CARES Act funding to subsidize water and sewer bills, to provide short-term and intermediate handwashing stations and dry toilets to unpiped households, and to build new homes that include in-home water and sanitation systems.

In light of the unique challenges facing rural Alaska during the COVID-19 pandemic, efforts to improve water, sanitation and hygiene access in remote communities need to be renewed and increased at the local, regional, state, and federal levels. Stakeholders across remote Alaska have made diligent efforts to reduce disease transmission, increase sanitization efforts, and reduce risk, but the threat of COVID-19 outbreak in remote communities is still very high and the consequences will have significant and far-reaching impacts on the people living there. The provision of in-home plumbing infrastructure, suitable community facilities, adequate healthcare, and appropriate financial support would help protect isolated communities get through the current pandemic and provide vital infrastructure necessary for community health under normal conditions. As we continue to navigate in unknown waters and shift to rebuilding, we hope that the inequities highlighted by the COVID-19 pandemic create a renewed focus on the underlying determinants of population health and the importance of access to basic water and sanitation services for all populations. 


\section{Author Contributions}

S.A., D.L.B., S.D., and L.E. conceptualized the manuscript and contributed to writing the original draft and editing. S.D. and S.A. developed the visualizations. T.H., D.L.B., E.B., B.R.B., P.C., A.D.D., D.M.D., M.B.H., and K.M. wrote sections of the paper and contributed to editing of the manuscript. All authors reviewed the final manuscript and approved it for this preprint submission.

\section{Acknowledgements}

Authors S.A., L.E., and M.B.H. acknowledge support from the National Science Foundation (award numbers 2033192, 2022590, 2022670).

\section{References}

Abou-Sabe, K., McFadden, C., Martinez, D., 2020. "Hit us at our core": Vulnerable Navajo Nation fears a second COVID-19 wave. NBC News.

Aboubakr, H.A., Sharafeldin, T.A., Goyal, S.M., 2020. Stability of SARS-CoV-2 and other coronaviruses in the environment and on common touch surfaces and the influence of climatic conditions: A review. Transbound. Emerg. Dis. 00, 1-17.

ADEC, 2013. Alaska Water and Sewer Challenge [WWW Document]. URL https://dec.alaska.gov/water/water-sewer-challenge/ (accessed 11.25.20).

Ahmed, W., Angel, N., Edson, J., Bibby, K., Bivins, A., O’Brien, J.W., Choi, P.M., Kitajima, M., Simpson, S.L., Li, J., others, 2020. First confirmed detection of SARS-CoV-2 in untreated wastewater in Australia: A proof of concept for the wastewater surveillance of COVID-19 in the community. Sci. Total Environ. 138764.

Altmann, D.M., Boyton, R.J., 2020. SARS-CoV-2 T cell immunity: Specificity, function, durability, and role in protection. ScieAltmann, D.M., Boyton, R.J., 2020. SARS-CoV-2 T cell Immun. Specificity, Funct. durability, role Prot. Sci. Immunol. 5.nce Immunol. 5, eabd6160.

Bar-On, Y.M., Flamholz, A., Phillips, R., Milo, R., 2020. Science Forum: SARS-CoV-2 (COVID-19) by the numbers. Elife 9, e57309.

Bennett, 2020. To stop coronavirus, Arctic communities took matters into their own hands. Can it last? [WWW Document]. Cryopolitics. URL https://www.cryopolitics.com/2020/08/25/communities-stop-coronavirus-arctic/\%0A (accessed 10.10.20).

Bhowmick, G.D., Dhar, D., Nath, D., Ghangrekar, M.M., Banerjee, R., Das, S., Chatterjee, J., 2020. Coronavirus disease 2019 (COVID-19) outbreak: some serious consequences with urban and rural water cycle. npj Clean Water 3, 1-8.

Blake, K., Kellerson, R., Simic, A., 2007. Measuring Overcrowding in Housing. U.S. Department of Housing and Urban Development Office of Policy Development and Research. 
392

393

394

395

396

397

398

399

400

401

402

403

404

405

406

407

408

409

410

411

412

413

414

415

416

417

418

419

420

421

422

423

424

425

426

427

Bogler, A., Packman, A., Furman, A., Gross, A., Kushmaro, A., Ronen, A., Dagot, C., Hill, C., Vaizel-Ohayon, D., Morgenroth, E., others, 2020. Rethinking wastewater risks and monitoring in light of the COVID-19 pandemic. Nat. Sustain. 1-10.

Brubaker, M., Berner, J., Chavan, R., Warren, J., 2011. Climate change and health effects in Northwest Alaska. Glob. Health Action 4, 8445.

CDC, 2020. CDC Handwashing: Clean Hands Save Lives [WWW Document]. URL https://www.cdc.gov/handwashing/faqs.html (accessed 11.25.20).

Chambers, M.K., Ford, M.R., White, D.M., Barnes, D.L., Schiewer, S., 2009. Transport of fecal bacteria by boots and vehicle tires in a rural Alaskan community. J. Environ. Manage. 90, 961-966.

Chen, J.T., Krieger, N., 2020. Revealing the Unequal Burden of COVID-19 by Income, Race/Ethnicity, and Household Crowding: US County Versus Zip Code Analyses. J. Public Heal. Manag. Pract. 27, S43-S56.

Chen, Y., Chen, L., Deng, Q., Zhang, G., Wu, K., Ni, L., Yang, Y., Liu, B., Wang, W., Wei, C., others, 2020. The presence of SARS-CoV-2 RNA in the feces of COVID-19 patients. J. Med. Virol. 92, 833-840.

Cheung, K.S., Hung, I.F.N., Chan, P.P.Y., Lung, K.C., Tso, E., Liu, R., Ng, Y.Y., Chu, M.Y., Chung, T.W.H., Tam, A.R., others, 2020. Gastrointestinal manifestations of SARS-CoV-2 infection and virus load in fecal samples from the Hong Kong cohort and systematic review and meta-analysis. Gastroenterology 159, 81-95.

Chia, P.Y., Coleman, K.K., Tan, Y.K., Ong, S.W.X., Gum, M., Lau, S.K., Lim, X.F., Lim, A.S., Sutjipto, S., Lee, P.H., others, 2020. Detection of air and surface contamination by SARSCoV-2 in hospital rooms of infected patients. Nat. Commun. 11, 1-7.

Choi, P.M., Tscharke, B.J., Donner, E., O’Brien, J.W., Grant, S.C., Kaserzon, S.L., Mackie, R., O'Malley, E., Crosbie, N.D., Thomas, K. V, others, 2018. Wastewater-based epidemiology biomarkers: past, present and future. TrAC Trends Anal. Chem. 105, 453-469.

Crits-Christoph, A., Kantor, R.S., Olm, M.R., Whitney, O.N., Al-Shayeb, B., Lou, Y.C., Flamholz, A., Kennedy, L.C., Greenwald, H., Hinkle, A., others, 2020. Genome sequencing of sewage detects regionally prevalent SARS-CoV-2 variants. medRxiv.

D’Amico, F., Baumgart, D.C., Danese, S., Peyrin-Biroulet, L., 2020. Diarrhea during COVID-19 infection: pathogenesis, epidemiology, prevention and management. Clin. Gastroenterol. Hepatol. 18, 1663-1672.

Deitz, S., Meehan, K., 2019. Plumbing poverty: mapping hot spots of racial and geographic inequality in US household water insecurity. Ann. Am. Assoc. Geogr. 109, 1092-1109.

DHSS, 2020a. Healthy Alaskans 2020: Leading Health Priorities [WWW Document]. URL http://hss.state.ak.us/ha2020/25LHI.htm (accessed 11.25.20). 
428

429

430

431

432

433

434

435

436

437

438

439

440

441

442

443

444

445

446

447

448

449

450

451

452

453

454

455

456

457

458

459

460

461

462

DHSS, 2020b. DHSS COVID-19 Media \& Communications [WWW Document]. URL http://dhss.alaska.gov/dph/Epi/id/Pages/COVID-19/communications.aspx\#cases

Eichelberger, L., 2019. Recognizing the dynamics of household water insecurity in the rapidly changing polar north: Expected uncertainties in access, quality, and consumption patterns in Niugtaq (Newtok), Alaska. World Dev. Perspect. 16, 100148.

Eichelberger, L., 2018. Household water insecurity and its cultural dimensions: preliminary results from Newtok, Alaska. Environ. Sci. Pollut. Res. 25, 32938-32951.

Eichelberger, L.P., 2011. Manufacturing insecurity: Power, water, waste, and the silences of sustainability and suffering in Northwest Alaska. PhD Diss. The University of Arizona.

Eichelberger, L.P., 2010. Living in utility scarcity: Energy and water insecurity in Northwest Alaska. Am. J. Public Health 100, 1010-1018. doi:10.2105/AJPH.2009.160846

Esper, F., Ou, Z., Huang, Y.T., 2010. Human coronaviruses are uncommon in patients with gastrointestinal illness. J. Clin. Virol. 48, 131-133.

Frick, A., Watkins, A., 2020. Summary of COVID-19 Hospitalizations - Alaska, January 1 through October 15, 2020 [WWW Document]. State Alaska Epidemiol. Bull. URL http://www.epi.alaska.gov/bulletins/docs/b2020_12.pdf (accessed 11.25.20).

Gravlee, C.C., 2020. Systemic racism, chronic health inequities, and COVID-19: A syndemic in the making? Am. J. Hum. Biol. 32, e23482.

Guerrero-Latorre, L., Ballesteros, I., Villacrés-Granda, I., Granda, M.G., Freire-Paspuel, B., Rios-Touma, B., 2020. SARS-CoV-2 in river water: Implications in low sanitation countries. Sci. Total Environ. 743, 140832.

Hathaway, E.D., 2020. American Indian and Alaska Native People: Social Vulnerability and COVID-19. J. Rural Heal. In-press.

Hennessy, T.W., Ritter, T., Holman, R.C., Bruden, D.L., Yorita, K.L., Bulkow, L., Cheek, J.E., Singleton, R.J., Smith, J., 2008. The relationship between in-home water service and the risk of respiratory tract, skin, and gastrointestinal tract infections among rural Alaska Natives. Am. J. Public Health 98, 2072-2078. doi:10.2105/AJPH.2007.115618

Hijnen, D., Marzano, A.V., Eyerich, K., GeurtsvanKessel, C., Giménez-Arnau, A.M., Joly, P., Vestergaard, C., Sticherling, M., Schmidt, E., 2020. SARS-CoV-2 transmission from presymptomatic meeting attendee, Germany. Emerg. Infect. Dis. 26, 1935.

Howard, G., Bartram, J., 2003. Domestic water quantity, service level and health. WHO Report. [WWW Document]. URL https://apps.who.int/iris/bitstream/handle/10665/67884/WHO_SDE_WSH_03.02.pdf

Isakbaeva, E.T., Khetsuriani, N., Beard, R.S., Peck, A., Erdman, D., Monroe, S.S., Tong, S., Ksiazek, T.G., Lowther, S., Smith, I.P., others, 2004. SARS-associated coronavirus 
transmission, United States. Emerg. Infect. Dis. 10, 225.

464

James, I., 2020. Waiting for water: On the Navajo Nation, long lines, scarce resources, a cry for solutions [WWW Document]. AZ Cent. URL https://www.azcentral.com/in$\mathrm{depth} /$ news/local/arizona-environment/2020/07/22/the-navajo-nations-wait-for-waterpersists-with-few-answers/3224889001/

Jepson, W., Budds, J., Eichelberger, L., Harris, L., Norman, E., O’Reilly, K., Pearson, A., Shah, S., Shinn, J., Staddon, C., others, 2017. Advancing human capabilities for water security: A relational approach. Water Secur. 1.

Jevšnik, M., Steyer, A., Zrim, T., Pokorn, M., Mrvič, T., Grosek, Š., Strle, F., Lusa, L., Petrovec, M., 2013. Detection of human coronaviruses in simultaneously collected stool samples and nasopharyngeal swabs from hospitalized children with acute gastroenteritis. Virol. J. 10, 46.

Joseph, N.P., Reid, N.J., Som, A., Li, M.D., Hyle, E.P., Dugdale, C.M., Lang, M., Betancourt, J.R., Deng, F., Mendoza, D.P., others, 2020. Racial/ethnic disparities in disease severity on admission chest radiographs among patients admitted with confirmed COVID-19: a retrospective cohort study. Radiology 202602.

Kakol, M., Upson, D., Sood, A., 2020. Susceptibility of Southwestern American Indian Tribes to Coronavirus Disease 2019 (COVID-19). J. Rural Heal. In press.

Kazama, S., Masago, Y., Tohma, K., Souma, N., Imagawa, T., Suzuki, A., Liu, X., Saito, M., Oshitani, H., Omura, T., 2016. Temporal dynamics of norovirus determined through monitoring of municipal wastewater by pyrosequencing and virological surveillance of gastroenteritis cases. Water Res. 92, 244-253.

Kim, G., 2020. 180 Chevak residents have been newly infected with COVID-19. What happened? [WWW Document]. Alaska Public Media. URL https://www.alaskapublic.org/2020/10/26/why-is-there-a-sudden-burst-of-covid-19-casesin-chevak/ (accessed 11.25.20).

Kim, J.-M., Kim, H.M., Lee, E.J., Jo, H.J., Yoon, Y., Lee, N.-J., Son, J., Lee, Y.-J., Kim, M.S., Lee, Y.-P., others, 2020. Detection and Isolation of SARS-CoV-2 in Serum, Urine, and Stool Specimens of COVID-19 Patients from the Republic of Korea. Osong Public Heal. Res. Perspect. 11, 112.

Kipkorir, V., Cheruiyot, I., Ngure, B., Misiani, M., Munguti, J., 2020. Prolonged SARS-Cov-2 RNA Detection in Anal/Rectal Swabs and Stool Specimens in COVID-19 Patients After Negative Conversion in Nasopharyngeal RT-PCR Test. J. Med. Virol. 92, 2328-2331.

Kitajima, M., Ahmed, W., Bibby, K., Carducci, A., Gerba, C.P., Hamilton, K.A., Haramoto, E., Rose, J.B., 2020. SARS-CoV-2 in wastewater: State of the knowledge and research needs. Sci. Total Environ. 139076.

Krammer, F., 2020. SARS-CoV-2 vaccines in development. Nature 586, 516-527. 
499

500

501

502

503

504

505

506

507

508

509

510

511

512

513

514

515

516

517

518

519

520

521

522

523

524

525

526

527

528

529

530

531

532

533

Krieger, N., 2020. ENOUGH: COVID-19, Structural Racism, Police Brutality, Plutocracy, Climate Change - and Time for Health Justice, Democratic Governance, and an Equitable, Sustainable Future.

Krieger, R., 2019. Commutes Across Alaska Are Common. Alaska Econ. Trends 39, 7-9.

KYUK, 2020. These Y-K Delta communities, including Bethel, waiving some utility costs during COVID-19 pandemic [WWW Document]. Alaska Public Media. URL https://www.alaskapublic.org/2020/04/03/these-y-k-delta-communities-including-bethelwaiving-some-utility-costs-during-covid-19-pandemic/

Lan, J., Ge, J., Yu, J., Shan, S., Zhou, H., Fan, S., Zhang, Q., Shi, X., Wang, Q., Zhang, L., others, 2020. Structure of the SARS-CoV-2 spike receptor-binding domain bound to the ACE2 receptor. Nature 581, 215-220.

Lodder, W.J., Buisman, A.M., Rutjes, S.A., Heijne, J.C., Teunis, P.F., de Roda Husman, A.M., 2012. Feasibility of quantitative environmental surveillance in poliovirus eradication strategies. Appl. Environ. Microbiol. 78, 3800-3805.

Lorenzo, M., Picó, Y., 2019. Wastewater-based epidemiology: current status and future prospects. Curr. Opin. Environ. Sci. Heal. 9, 77-84.

Lu, D., Huang, Z., Luo, J., Zhang, X., Sha, S., 2020. Primary concentration--The critical step in implementing the wastewater based epidemiology for the COVID-19 pandemic: A minireview. Sci. Total Environ. 747, 141245.

Lu, R., Zhao, X., Li, J., Niu, P., Yang, B., Wu, H., Wang, W., Song, H., Huang, B., Zhu, N., others, 2020. Genomic characterisation and epidemiology of 2019 novel coronavirus: implications for virus origins and receptor binding. Lancet 395, 565-574.

Mao, K., Zhang, H., Yang, Z., 2020. Can a paper-based device trace COVID-19 sources with wastewater-based epidemiology? Environ. Sci. Technol. 54, 3733-3735.

Mattos, K., Eichelberger, L., Warren, J., Dotson, A., Hawley, M., Linden, K., 2020. Household Water, Sanitation, and Hygiene Practices Impact Pathogen Exposure in Remote, Rural, Unpiped Communities. Environ. Eng. Sci. doi:https://doi.org/10.1089/ees.2020.0283

McKinney, K.R., Gong, Y.Y., Lewis, T.G., 2006. Environmental transmission of SARS at Amoy Gardens. J. Environ. Health 68, 26.

Medema, G., Heijnen, L., Elsinga, G., Italiaander, R., Brouwer, A., 2020. Presence of SARSCoronavirus-2 RNA in sewage and correlation with reported COVID-19 prevalence in the early stage of the epidemic in the Netherlands. Environ. Sci. Technol. Lett. 7, 511-516.

Meehan, K., Jurjevich, J.R., Chun, N.M.J.W., Sherrill, J., 2020. Geographies of insecure water access and the housing--water nexus in US cities. Proc. Natl. Acad. Sci. 117, 28700-28707.

Mosites, E., Lefferts, B., Seeman, S., January, G., Dobson, J., Fuente, D., Bruce, M., Thomas, T., 
Hennessy, T., 2020. Community water service and incidence of respiratory, skin, and gastrointestinal infections in rural Alaska, 2013--2015. Int. J. Hyg. Environ. Health 225, 113475.

Murakami, M., Hata, A., Honda, R., Watanabe, T., 2020. Letter to the editor: wastewater-based epidemiology can overcome representativeness and stigma issues related to COVID-19. Environ. Sci. Technol. 54, 5311.

Peng, L., Liu, J., Xu, W., Luo, Q., Chen, D., Lei, Z., Huang, Z., Li, X., Deng, K., Lin, B., others, 2020. SARS-CoV-2 can be detected in urine, blood, anal swabs, and oropharyngeal swabs specimens. J. Med. Virol. 92, 1676-1680.

Petersen, E., Koopmans, M., Go, U., Hamer, D.H., Petrosillo, N., Castelli, F., Storgaard, M., A1 Khalili, S., Simonsen, L., 2020. Comparing SARS-CoV-2 with SARS-CoV and influenza pandemics. Lancet Infect. Dis. 20, e238-e244.

Pettit, K.L.S., 2014. Continuity and change: demographic, socioeconomic, and housing conditions of American Indians and Alaska Natives. US Department of Housing and Urban Development, Office of Policy Development.

Pindus, N., Kingsley, T., Biess, J., Levy, D., Simington, J., Hayes, C., 2017. Housing needs of American Indians and Alaska Natives in Tribal areas: A report from the assessment of American Indian, Alaska Native, and Native Hawaiian housing needs: Executive summary, US Department of Housing and Urban Development, Office of Policy Development and Research.

Rafa, N., Uddin, S.M.N., Staddon, C., 2020. Exploring challenges in safe water availability and accessibility in preventing COVID-19 in refugee settlements. Water Int. 1-6.

Rahman, B., Sadraddin, E., Porreca, A., 2020. The basic reproduction number of SARS-CoV-2 in Wuhan is about to die out, how about the rest of the World? Rev. Med. Virol. 30, e2111.

Richardson, S., Hirsch, J.S., Narasimhan, M., Crawford, J.M., McGinn, T., Davidson, K.W., Barnaby, D.P., Becker, L.B., Chelico, J.D., Cohen, S.L., others, 2020. Presenting characteristics, comorbidities, and outcomes among 5700 patients hospitalized with COVID-19 in the New York City area. JAMA 323, 2052-2059.

Riggs, E., Hughes, J., Irvin, D., Leopard, K., 2017. An Overview of Clean Water Access Challenges in the United States, Global Water Challenge and the Environmental Finance Center, School of Government, University of North Carolina: Chapel Hill, NC, USA.

Rodriguez-Lonebear, D., Barceló, N.E., Akee, R., Carroll, S.R., 2020. American Indian Reservations and COVID-19: Correlates of Early Infection Rates in the Pandemic. J. Public Heal. Manag. Pract. 26, 371-377.

Roy, A., Basu, A., Pramanick, K., 2020. Water, Sanitation, Hygiene and Covid-19 pandemic: a global socioeconomic analysis. medRxiv. 
570 571

572

573

574

575

576

577

578

579

580

581

582

583

584

585

586

587

588

589

590

591

592

593

594

595

596

597

598

599

600

601

602

603

Shang, J., Wan, Y., Luo, C., Ye, G., Geng, Q., Auerbach, A., Li, F., 2020. Cell entry mechanisms of SARS-CoV-2. Proc. Natl. Acad. Sci. 117, 11727-11734.

Smiley, S.L., Agbemor, B.D., Adams, E.A., Tutu, R., 2020. COVID-19 and water access in SubSaharan Africa: Ghana's free water directive may not benefit water insecure households. African Geogr. Rev. 1-7.

Smith, D.W., 1996. Cold regions utilities monograph. American Society of Civil Engineers.

Sohns, A., Ford, J.D., Adamowski, J., Robinson, B.E., 2020. Participatory Modeling of Water Vulnerability in Remote Alaskan Households Using Causal Loop Diagrams. Environ. Manage. 1-17.

Staddon, C., Everard, M., Mytton, J., Octavianti, T., Powell, W., Quinn, N., Uddin, S.M.N., Young, S.L., Miller, J.D., Budds, J., others, 2020. Water insecurity compounds the global coronavirus crisis. Water Int. 1-7.

Stoler, J., Jepson, W.E., Wutich, A., 2020. Beyond handwashing: Water insecurity undermines COVID-19 response in developing areas. J. Glob. Health 10, 010355.

Thomas, T.K., Hickel, K., Heavener, M., 2016. Extreme water conservation in Alaska: limitations in access to water and consequences to health. Public Health 137, 59-61.

UNICEF, 2019. Progress on household drinking water, sanitation, and hygiene 2000-2017. Special focus on inequalities. New York.

van Dorn, A., Cooney, R.E., Sabin, M.L., 2020. COVID-19 exacerbating inequalities in the US. Lancet 395, 1243-1244.

Wilder, J.M., 2020. The disproportionate impact of COVID-19 on racial and ethnic minorities in the United States. Clin. Infect. Dis. DOI: 10.1093/cid/ciaa959.

Wiltse, N., Madden, D., 2018. Alaska Housing Assessment Statewide Housing Characteristics. Alaska Housing Finance Corporation.

Xiao, F., Sun, J., Xu, Y., Li, F., Huang, X., Li, H., Zhao, Jingxian, Huang, J., Zhao, Jincun, 2020. Infectious SARS-CoV-2 in feces of patient with severe COVID-19. Emerg. Infect. Dis. 26, 1920-1922.

YKHC, 2020. Disinfection without running water [WWW Document]. URL https://www.ykhc.org/covid-19-disinfection-without-running-water/ (accessed 11.26.20).

Zar, H.J., Dawa, J., Fischer, G.B., Castro-Rodriguez, J.A., 2020. Challenges of COVID-19 in children in low-and middle-income countries. Paediatr. Respir. Rev. 35, 70-74.

Zhu, N., Zhang, D., Wang, W., Li, X., Yang, B., Song, J., Zhao, X., Huang, B., Shi, W., Lu, R., others, 2020. A novel coronavirus from patients with pneumonia in China, 2019. N. Engl. J. Med. 382, 727-733. 
604 